ENTREVISTA

\title{
A educação em um mundo cada vez mais caótico
}

O professor norte-americano David Thornburg, PhD pela Universidade de Illinois, entrevistou seu compatriota Jamais Cascio, futurista de renome mundial cujas perspectivas sobre vários tópicos são compartilhadas em seu site, openthefuture.com. "Jamais Cascio se refere a si próprio como um generalista que se distrai facilmente, uma descrição que também se aplica a mim", diz David Thornburg. O tema principal dessa conversa foi a educação, mas outros assuntos pertinentes à sociedade contemporânea também foram abordados.
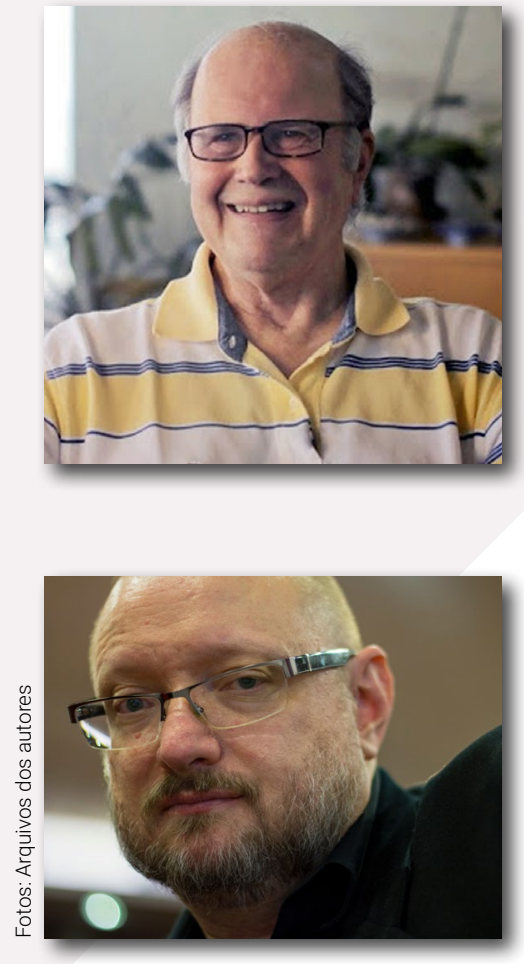

David Thornburg é pesquisador, inventor e educador. Participa frequentemente de conferências sobre educação em todo o mundo. Foi professor na Universidade de Stanford, na Universidade de São Paulo e na Universidade Walden, entre outras. É autor de diversos livros, entre eles From the campfire to the holodeck: creating engaging and powerful 21st century learning environments, e atualmente estuda diferentes aspectos da exploração espacial. Após receber seu PhD pela Universidade de Illinois, Thornburg passou a primeira década de sua carreira no famoso Xerox Palo Alto Research Center. E-mail: ddthornburg@gmail.com

Jamais Cascio foi apontado pela revista Foreign Policy como um dos 100 maiores pensadores do mundo. Escreve sobre a interseção de tecnologias emergentes, dilemas ambientais e transformação cultural, tendo se especializado na criação de cenários plausíveis de futuro. Seu trabalho enfoca a importância do pensamento sistêmico de longo prazo, enfatizando o poder da abertura, da transparência e da flexibilidade como catalisadores para a construção de uma sociedade mais resiliente. É autor de Hacking the Earth understanding the consequenses of geoengeneering. E-mail: cascio@openthefuture.com 
DT - Bem-vindo, Jamais, estou feliz que você tenha tido tempo para explorar algumas ideias comigo.

JC - É um prazer, David. No que você está pensando?

DT - Você sugeriu que entramos em um mundo BANI (Brittle, Anxious, Nonlinear and Incomprehensible - Frágil, Ansioso, Não-linear e Incompreensível, em tradução livre), conceito que você criou em "substituição" ao conceito de mundo VUCA (Volatile, Uncertain, Complex and Ambiguous - Volátil, Incerto, Complexo e Ambíguo, em tradução livre), cunhado na década de 1990. Gostaria que você expandisse seu raciocínio por trás do mundo BANI com exemplos de cada um desses aspectos.

JC - Vamos lá. Criei o BANI em parte como uma forma de esboçar um enquadramento para um mundo que foi além de ser apenas complexo e tornou-se totalmente caótico. Tenho trabalhado fazendo previsões globais há mais de 25 anos e o BANI foi uma tentativa de dar uma estrutura formal a muito do que eu vinha estudando há tanto tempo. O VUCA não parecia mais útil porque simplesmente estava em toda parte. "Eu como VUCA no café da manhã", é uma frase que eu usava de brincadeira.

Frágil é um termo que comecei a usar ao escrever sobre resiliência em meados dos anos 2000. Eu o uso para me referir a sistemas que exibem todas as evidências de força e solidez, mas se desfazem com um certo nível de pressão. Não é que eles veem suas utilidades se degradarem quando sobrecarregados, um sistema frágil pode ir de utilizável a completamente quebrado. Neste exato momento, o melhor exemplo de sistema frágil em que consigo pensar é a democracia e a governança democráticas, em que nós, nos Estados Unidos, assim como em muitas partes do mundo, incluindo o Brasil, reconhecemos que um sistema político aparentemente robusto pode com muita rapidez ser empurrado para a beira do colapso por um pequeno grupo de atores dentro do sistema.

Um exemplo menos pontual são as monoculturas agrícolas, que apresentam um desempenho muito bom quando não há condições adversas, mas podem ser vulneráveis a ataques direcionados, como espécies específicas de pragas.

Ansioso (ou indutor de ansiedade) é um termo que apare muito mais recentemente em meu trabalho. Para mim, surgiu da leitura sobre as experiências de pessoas mais jovens nos últimos anos e da referência frequente a se sentirem sem qualquer controle sobre as mudanças que afetam diretamente suas vidas. Cada opção parece potencialmente desastrosa. As condições que desencadeiam a ansiedade podem ser encontradas em todos os lugares. Este é o elemento do BANI que, para mim, parece mais pessoal. As escolhas sobre como lidar com as perturbações climáticas são o principal exemplo.

O não-linear reflete o caos que mencionei antes, mas também carrega uma conexão com uma questão climática sobre a qual muitas pessoas não falam. 0 aquecimento global antropogênico é um processo histérico, o que significa que várias vezes existe uma distância ou defasagem entre as causas e os efeitos. De modo geral, agora estamos sentindo os impactos do grande aumento de carbono na 
atmosfera no final do século passado. Poderíamos interromper todas as emissões de carbono causadas pelo homem em todo o mundo agora e ainda assim ver o aquecimento contínuo do planeta por algumas décadas. E não apenas altas temperaturas contínuas, que permanecerão conosco por séculos. De forma mais ampla, a não linearidade descreve processos em que há extrema desproporcionalidade entre causas e efeitos. As pandemias são frequentemente citadas como exemplos de não-linearidade na natureza.

A incompreensibilidade é um tanto irônica, mas descreve um mundo no qual as consequências da interação de ações e escolhas são funcionalmente impossíveis de entender. Elas não fazem sentido porque os processos subjacentes são muito caóticos, muito complexos, muito grandes para o cérebro humano compreender por completo. 0 trabalho com inteligência artificial e o aprendizado de máquina aparecem aqui - já estamos em um ponto em que os fundamentos dos algoritmos para as escolhas das máquinas em sistemas de aprendizado muitas vezes não podem ser explicados, mesmo que funcionem como desejado. Adicionar dados, nossa solução usual para coisas que não podemos entender, tende a piorar o problema, não a melhorar.

DT - Hoje a educação tem como uma de suas principais premissas preparar o indivíduo para lidar com o pensamento complexo, a transdisciplinaridade, conceitos que lutam contra a ideia de divisão do conhecimento em disciplinas, a fragmentação do conhecimento etc. Mas como desenvolver tais conceitos neste mundo tão incompreensível e instável? Como promover a aprendizagem ao longo da vida quando o mundo tem múltiplas possibilidades? Novamente, da minha perspectiva, estamos com quase $25 \%$ no século XXI transcorridos, mas nosso ensino em áreas como matemática não mudou muito desde que os livros de matemática foram traduzidos do latim para o inglês.

JC - Em um mundo como este, a especificidade pode ser mortal. Ou seja, se houver um foco muito estreito, corre-se o risco de uma mudança repentina tornar determinada área focal irrelevante. 0 esforço que você descreve para lutar contra a ideia de dividir o conhecimento é exatamente o que se faz necessário.

Minha opinião sobre isso vem em parte da biologia, especificamente da teoria da estratégia reprodutiva das espécies. Uma estratégia do tipo "K" envolve colocar um grande esforço e energia para criar descendentes altamente especializados para o meio ambiente. Enquanto esse ambiente persistir, a prole florescerá e dominará seu nicho. Gorilas costumam ser citados como o exemplo clássico disso. Por outro lado, uma estratégia do tipo "r" envolve colocar muito pouco esforço e energia nos filhos, mas produzir muitos deles, imaginando que ao menos alguns sobreviverão. As estratégias " $r$ " funcionam melhor quando o ambiente está em fluxo, quando as condições estão mudando rapidamente. As "ervas daninhas" geralmente são citadas nesse caso - espécies que são resistentes e podem viver em vários ambientes. 
Basicamente, precisamos ser pensadores " $r$ " tanto quanto pudermos em um mundo como este.

Para quem não conhece, "K" e "r" são termos da biologia evolutiva. Foram cunhados por Robert MacArthur e Edward Wilson em 1967, no livro The Theory of Island Biogeography. Não é mais o modelo científico dominante, mas permanece útil como estrutura para o pensamento.

DT - De uma perspectiva sistêmica, isso se parece um pouco com as ideias de Gilles Deleuze e Félix Guattari a respeito da distinção entre estruturas rizomais e arbóreas aplicadas à filosofia. Em sistemas rizomais, cada parte do sistema está conectada a todas as outras partes. Em sistemas arbóreos, cada parte é finita em seu alcance. Os sistemas rizômicos (como muitas ervas daninhas) são altamente resilientes, ao contrário de muitas estruturas de árvores, que podem ser quebradas com bastante facilidade. Como dizem os autores, "Faça rizomas, não raízes, nunca plante! Não semeie, cresça rebentos! Não seja um ou múltiplos, seja multiplicidade!".

JC - Faz sentido.

DT - Gostaria de tentar entender o papel do educador em um mundo onde tudo se comunica, todos transmitem conhecimento, tudo informa. Como planejamos e administramos a educação do século XXI? Por exemplo, a estudante Darnella Frazier, de 17 anos, filmou o assassinato de George Floyd com a câmera de seu celular. Que implicações isso tem para a educação hoje?

JC - Para mim, é a importância de se ter múltiplas perspectivas. Estamos cada vez mais nos movendo para um mundo onde a diversidade de pontos de vista é crucial para lutar contra a falsidade. Com o vídeo, isso é literalmente verdade. Quanto mais câmeras gravam um evento, de tantas posições quanto possível, mais difícil se torna negar a realidade do evento. A implicação não intencional da gravação de George Floyd é que dependemos muito da documentação, mas está ficando cada vez mais fácil falsificar essa documentação de maneira crível. Há uma necessidade real de aprendermos a ser pensadores críticos quanto à documentação, não apenas aceitar que algo é verdadeiro porque parece verdadeiro e se encaixa em nossa visão de mundo.

DT - Você acredita que a requalificação é um caminho possível para profissionais em constante transformação, ou acha que a situação de exclusão produtiva será ampliada, empurrando cada vez mais profissionais para a informalidade?

JC - Uma maneira de pensar a "requalificação" é como uma implicação do surgimento de uma variedade de métodos de educação não tradicionais, como os vídeos do YouTube, que estão começando a desafiar com sucesso a utilidade da pedagogia convencional. Também pode se referir aos ataques à expertise que vemos acontecendo, onde "faça sua pesquisa" significa "leia este discurso retórico no Facebook". Eu gostaria de ter uma boa resposta para tudo isso. 
DT - Creio que precisamos ajudar professores e alunos a desenvolver as habilidades para identificar a desinformação, seja ela acidental ou intencional. Parece-me que a noção de mídia imparcial foi amplamente substituída por a de uma mídia que promove amplamente um ponto de vista em detrimento de outros.

JC - Em termos de abordagens de ensino, suponho que o elemento mais importante é a abordagem transdisciplinar: estar exposto às conexões entre diferentes domínios do conhecimento. Então, em vez de ter silos de diferentes tópicos ao longo do dia, ter mais interseções entre esses diferentes domínios do conhecimento.

DT - Este é um bom ponto. Por exemplo, tenho feito algumas pesquisas sobre a morfologia das plantas que me levaram ao Journal of Computational Biology, um periódico que publica artigos de autores cujos trabalhos abrangem os dois campos.

JC - Outro domínio sobre o qual os professores devem pensar é o do ceticismo. Principalmente em uma era de manipulação digital, é importante saber ser cético de uma forma útil, não o ceticismo no sentido de negar tudo. Isso significa pesquisar as fontes de informação e aplicar o ceticismo que realmente é útil para tentar encontrar os argumentos subjacentes. Onde estão os dados subjacentes? O que está faltando? Como os dados estão sendo usados? Isso é especialmente importante em um mundo que lida com mudanças climáticas, pandemias como a de covid-19 e desafios políticos, tudo ao mesmo tempo. Este é o mundo em que nossos filhos estão crescendo.

DT - De fato! Eu acredito, e seus trabalhos apoiam esse sentimento de que podemos forjar um futuro positivo para nosso planeta, e estou ansioso para os próximos anos, à medida que esse novo futuro se desdobra. 